Author postprint, final version as submitted to AJL.

Anna Wierzbicka \& Cliff Goddard (2017): Talking about our Bodies and their Parts in Warlpiri, Australian Journal of Linguistics, 38(1), 31-62. DOI: 10.1080/07268602.2018.1393862

\title{
Talking about our bodies and their parts in Warlpiri
}

\author{
Anna Wierzbicka \& Cliff Goddard \\ Australian National University and Griffith University
}

Linguists generally assume that all languages have some words for parts of the human body such as 'head', 'hands', 'mouth' and 'legs', but it is not so widely agreed that speakers of all languages can speak — or even consciously think - of the designata of such words as 'parts of the body'. In particular, it has been claimed that the Australian language Warlpiri lacks any suitable lexical equivalent of 'part(s)'. Using data from the Warlpiri English Encyclopedic Dictionary, this study contests this claim, arguing that the relevant sense of 'part' exists in Warlpiri as one sense of the polysemous closed-class item yangka (whose main meaning can be stated, roughly, as 'that one, you know the one'). Our argument is framed within the Natural Semantic Metalanguage (NSM) approach to meaning analysis, according to which meanings are stated as substitutable, cross-translatable paraphrases. NSM researchers have long maintained that PART(S) is a universal semantic prime, i.e. an indefinable meaning expressible by words or phrases in all human languages. The study also considers broader issues to do with semantic theory, polysemy and translation.

Keywords: Semantics of Body Parts; Vernacular Definitions; Natural Semantic Metalanguage (NSM); Semantic Universals; Australian Languages; Warlpiri; Language Documentation

\section{Talking and thinking about human bodies}

Linguists generally assume that all languages have some words for parts of the human body words such as 'head', 'hands', 'legs', 'eyes', 'ears', 'mouth', and so on (Brown 1976; Andersen 1978; Majid et al. 2006), but it is not so widely agreed that speakers of all languages can speak of the designata of such words as 'parts of the body' or even that they can think of them as 'parts of the body'. Linguists who work in the Natural Semantic Metalanguage (NSM) framework, such as the present authors, have hypothesized for many years that speakers of all languages can indeed talk about human bodies in this way, because all languages provide their speakers with words which make such talk possible, i.e. words that can express meanings like 'part of someone's body' (Goddard \& Wierzbicka 1994; Goddard 2008; Wierzbicka 1996, 2007). But the issue is contested, with some linguists claiming that in certain languages such meanings cannot be expressed at all, because the languages lack words for 'body' or for 'part', and, consequently, expressions like 'part of someone's body' cannot be formed. As we see it, this problem is of great inherent interest, and not just for linguists. After all, the body is our anchor in the world [Note 1] and our understanding of what human 
bodies are like is, or may be, one of the most fundamental aspects of what we, humans, share (cf. Wierzbicka 2014a).

In this paper we focus chiefly on the Warlpiri language of Central Australia, which according to Nash (2014) is one of several Australian languages which lacks a lexical equivalent of the proposed NSM semantic prime PART. Extensive lexicographic documentation of Warlpiri is available in the Warlpiri English Encyclopedic Dictionary (Laughren, Hale \& Warlpiri Lexicography Group 2006; henceforth: Warlpiri Dictionary). We seek to interrogate the material included in the Warlpiri Dictionary (both Warlpiri sentences and their English translations) to make the case that Warlpiri speakers can and do talk about "parts of the body". Later in the paper we broaden the discussion in order to position our findings in cross-linguistic perspective and to consider the implications for language documentation and for translation practice.

We begin by briefly reporting on earlier debates about the universality of the concept of 'part' or 'parts' and about the NSM framework.

\section{The NSM framework and the claimed universality of 'part'}

We will be approaching the Warlpiri data about the body from the standpoint of NSM semantics (Wierzbicka 1996; Goddard 2011; Goddard \& Wierzbicka 2014a, 2014b). Briefly, the NSM framework assumes that in all languages one can identify a set of irreducibly simple lexical meanings, termed semantic primes. On the basis of a decades-long program of crosslinguistic investigation, 65 semantic primes have been identified, which are believed to exist in all or most languages. The primes and their grammar of combination constitute a minilanguage in terms of which the myriad complex lexical meanings of the world's languages can be paraphrased. This shared lexical and grammatical core is termed the Natural Semantic Metalanguage (NSM). It has as many versions as there are languages, so there is English NSM, Spanish NSM, Chinese NSM, and so on; see e.g. Goddard \& Wierzbicka (eds. 2002); Peeters (ed. 2006), Goddard (ed. 2008). For practical purposes, English NSM is often used as the lingua franca of semantic interpretations, but other NSMs are also used in various NSM publications.

The full set of semantic primes is given in its English version in Table 1. Comparable tables exist for about 25 languages (a provisional Warlpiri version is given in Appendix 1). Because the same inventory is in evidence in widely diverse languages, and because the meanings are so simple and basic that they are known to all speakers of a language, including children, NSM researchers believe it is reasonable to regard semantic primes not merely as 
linguistic but equally as conceptual in nature. As can be seen, the inventory of semantic primes includes BODY and PART, which are at the heart of the present investigation. The hypothesis that the human body can be conceptualized, universally, in terms of 'parts', depends of course on the assumption that the concept of PART itself is universal. Equally, of course, it depends on the universality of the concept BODY, but this is a point which we regard as settled (Wierzbicka 2007), and we are not going to reopen that debate here: our focus is entirely on PART.

Table 1: Semantic primes, English exponents (after Goddard \& Wierzbicka 2014a)

\begin{tabular}{|l|r|}
\hline I, YOU, SOMEONE, SOMETHING THING, PEOPLE, BODY & substantives \\
\hline KINDS, PART HAVE PARTS & relational substantives \\
\hline THIS, THE SAME, OTHER ELSE & determiners \\
\hline ONE, TWO, SOME, ALL, MUCH MANY, LITTLE FEW & quantifiers \\
\hline GOOD, BAD & evaluators \\
\hline BIG, SMALL & descriptors \\
\hline KNOW, THINK, WANT, DON'T WANT, FEEL, SEE, HEAR & speech \\
\hline SAY, WORDS, TRUE & actions, events, movement \\
\hline DO, HAPPEN, MOVE & possession \\
\hline BE (SOMEWHERE), THERE IS, BE (SOMEONE/SOMETHING) & location, existence, specification \\
\hline (IS) MINE & time \\
\hline LIVE, DIE & place \\
\hline TIME WHEN, NOW, BEFORE, AFTER, A LONG TIME, A SHORT TIME, FOR & leath \\
\hline SOME TIME, MOMENT & logical concepts \\
\hline PLACE WHERE, HERE, ABOVE, BELOW, FAR, NEAR, SIDE, INSIDE, & augmentor, intensifier \\
\hline NOUCH & similarity \\
\hline VERY, MORE & \\
\hline LIKE & \\
\hline
\end{tabular}

Notes: - Exponents of primes can be polysemous, i.e. they can have other, additional meanings - Exponents of primes may be words, bound morphemes, or phrasemes - They can be formally complex • They can have language-specific combinatorial variants (allolexes, indicated with $\sim$ ) $\bullet$ Each prime has well-specified syntactic (combinatorial) properties.

In NSM work, the assumption that PART (or, PARTS) is a semantic and conceptual prime was adopted as a working hypothesis from the outset, in Wierzbicka's (1972) book Semantic Primitives. The hypothesis was re-affirmed a decade later in Lingua Mentalis (Wierzbicka 1980), which included several dozen tentative explications of body-part words. The matter was presented as open in Goddard (1989), who pointed to the need for further empirical and theoretical investigations, but, after some further investigations, the hypothesis was reaffirmed in Semantics: Primes and universals (Wierzbicka 1996). By that time (the mid-1990s), however, the universality of 'part' had become a controversial issue, partly because the earlier NSM claims on the subject were often misunderstood. In response to various dissenting comments, one of the present authors wrote: 
PART is a controversial primitive, partly [...] because many languages don't have a word with a range of similar use to that of the English noun part, and partly because some languages don't seem to have a word for part at all. In proposing PART as a universal semantic primitive, therefore, it is important, first of all, to clarify which uses of the English part are meant to illustrate the postulated primitive; and second, to examine how the meaning in question is expressed in a language which doesn't seem to have a word corresponding to the English part at all. (Wierzbicka 1996: 60; see also pp. 142-3)

Trying to clarify the issue, Wierzbicka (1996: 61) observed, inter alia, that cultures differ in the amount of interest they show in the concept of PARTS: "As argued in Goddard 1989, modern Western culture places a great emphasis on viewing various aspects of reality in terms of complexes analysable into 'parts', whereas, for example, Australian Aboriginal culture does not". But she insisted that even in cultures "whose speakers are less inclined to talk about 'parts' in the abstract (in contrast to heads, feet, handles, and other specific kinds of 'parts')", the concept of PART can nonetheless be expressed.

The issue of the universality of PART was discussed again, at some length, in Goddard's (2002) paper 'The search for the shared semantic core of all languages' in Meaning and Universal Grammar, where he wrote:

Linguists seem to agree that the part-whole relationship is fundamental to the vocabulary structure of all languages, but there are certainly languages which do not have a unique lexical form for the postulated semantic prime PART (OF). This does not necessarily mean, however, that these languages lack a lexical unit with the meaning PART. In three unrelated languages in which such an apparent gap has been investigated (Acehnese, Mangaaba-Mbula, Yankunytjatjara) it appears that PART exists as the meaning of a lexical unit of the same lexeme which can also mean SOMETHING, THING, or WHAT.

In these languages the meaning PART is expressed when the relevant lexical form is used in a grammatical construction associated with possession. (It is as if instead of saying, for example, 'the nose is a part of the face' one says 'the nose is a thing of the face'.) (Goddard 2002: 30)

These statements were illustrated with the following examples from three unrelated languages, using data from an earlier collective volume (Goddard and Wierzbicka eds. 1994):

Yankunytjatjara

$\begin{array}{lll}\text { - Puntu kutju,palu } & \text { kutjupa-kutjupa tjuta-tjara. } \\ \text { body one but } & \text { something-RDP } & \text { many-having }\end{array}$

'(It is) one body, but with many parts.' (from Goddard 1994b: 256) 
Acehnese

$\begin{array}{ll}\text { - Bakgeuritanangèn na } & \text { lè peue. } \\ \text { at vehicle wind there.is manywhat/something }\end{array}$

'A bicycle (lit. wind-vehicle) has many parts.' (adapted from Durie et al. 1994: 195)

Mangaaba-Mbula

- Iti tomtom na koroy-ya-nda boozo kumbu-ndu, nama-nda....

we person GIV thing-NMZ-our many leg-our head-our

'We people, our parts are many: our legs, our heads, ...' (adapted from Bugenhagen 1994: 103)

Thus, according to NSM research, in some lexicogrammatical contexts PART can have an unambiguous exponent in a word which in other contexts means 'thing' or 'something'. Nonetheless, in a major edited collection (Majid et al. 2006) on body-parts, several contributors contended that in the languages they studied there is no word for PART and they saw this as contrary to the NSM position. For example, Gaby (2006: 207) reported "the apparent lack of an expression corresponding to part of" in the Australian language Kuuk Thaayorre" and commented that "this runs counter to Wierzbicka's (1994, p.489) proposition that the relational concept part of is a (universally lexicalized) semantic primitive". These claims were countered with new data and analyses in Wierzbicka's (2007) paper 'Bodies and their parts: an NSM approach to semantic typology', which strongly reasserted the universality of the concept PART.

As mentioned, David Nash (2014: 84) has stated: "the proposed semantic prime PART is not readily translated in a number of Australian languages (Dalabon and Warlpiri included)". Contra Nash, we hope to show that, at least in certain key contexts to do with parts of the body, the notion of PART does have a lexical and semantic match in Warlpiri, namely, the word yangka, in one of its senses and grammatical frames. We acknowledge, however, that this match comes from an unexpected direction, since yangka is a closed-class word, analogous in some ways to English 'that' or 'that one'. For this reason, it is perhaps understandable that Nash (like other Australianists who have seemed confident that there is no word for 'part' in their language of study) has not noticed this possibility. If we examine Nash's discussion in more detail, however, it emerges that he was, apparently, not particularly alert to the possibility that a potential exponent could be polysemous, but was focused, rather, on the idea of a 'dedicated' exponent. He writes that the translatability of PART:

... has long been a point of contention with NSM: in the inventories of 'primes' complied by Goddard \& Wierzbicka (1994), Evans (1994: 222-3) found it difficult to identify the exponent of PART in Kayardild, as did Harkins \& Wilkins (1994: 303-4, 309) for Arrernte [...] Dalabon is another such language: no lexical unit corresponding 
to PART is recorded in the sizeable dictionary (Evans et al. 2004); 'Dalabon does not have a dedicated expression meaning "part of".' (Ponsonnet 2012: 359) (Nash 2014: 84)

Presumably the phrase 'a dedicated expression' means an expression which has no meaning other than PART. Yet, as we are emphasising here, NSM researchers have never posited the existence of any such 'dedicated expressions' (indeed, they have never even used the phrase 'dedicated expression'), but on the contrary have repeatedly stressed that they were not positing a one-to-one correspondence between primes and words. For example, when Goddard (1994a: 13) formulated the 'Strong Lexicalisation Hypothesis': "Every semantically primitive meaning can be expressed through a distinct word, morpheme or fixed phrase in a given language", he immediately went on to stress that no one-to-one correspondence between primes and forms was meant:

This does not entail that there should be a single unique form for each primitive. Some languages have several forms (allolexes or allomorphs of the same item) functioning as contextual variants expressing the same primitive meaning. Conversely, it sometimes happens that the same form serves as an exponent of different primitives, although their distinct syntactic frames make it appropriate to recognise polysemy. (Goddard 1994a: 13)

We will return to the issue of the polysemy and allolexy of semantic primes in typological perspective toward the end of this paper. At this point, however, we are ready to commence our examination of material from the Warlpiri Dictionary.

\section{The Warlpiri Dictionary Project}

The Warlpiri Dictionary is impressive in its scope and quality. Corris et al. (2004) describe the data files in the following way:

The Warlpiri dictionary [...] data files comprise about 10,000 headwords, including sub-entries, organized as Warlpiri-English, with fine sense distinctions and lengthy definitions in English and often in Warlpiri, and extensive exemplification. Printed in full on A4 pages in a 10 point font, it would comprise over 2,000 pages. (Corris et al. 2004: 38)

As explained by the Project's founder, Ken Hale, the purpose from the outset was to compile lexicographic resource material going far beyond the scope of most conventional dictionaries (Laughren \& Nash 1983). As Hale emphasized, the primary interest was in exploring the lexical resources of the language, in part by tapping into the knowledge of Warlpiri consultants. This was in accordance with a theme developed earlier in Casagrande 
and Hale's (1967) article 'Semantic relationships in Papago folk-definitions', in which they wrote:

Every language must thus in some degree serve as its own metalanguage to explicate semantic usage. Here then is a universal linguistic need. In Western and other literate cultures we have recourse to dictionaries, laboriously compiled by learned men, but speakers of unwritten languages must necessarily be their own lexicographers. (Casagrande \& Hale 1967: 165)

Casagrande \& Hale (1967: 165-66) quoted Uriel Weinreich (1962) on the value of letting "speakers of a language...themselves (to) suggest the proper types of conditions for the meanings of the various terms in their language", adding that this was "a position which we heartily endorse".

Evidently the same conviction inspired Hale's approach to his work with Warlpiri consultants, of which he wrote:

In the course of this work, several gifted speakers of Warlpiri were asked to compose oral essays (on tape) on the meanings and onomasiology of individual lexical items appears in IWDS [Introduction to Wailbry (sic.) Domains and Selection]. This resulted in a sizable increase in lexical inventory, because the essays themselves introduced many new items. Most important, however, it provided an extensive body of textual material containing not only extremely valuable commentary on the meanings of words and their uses, but also much contextual information of great relevance to our concerns in this project. (Hale 1983: 80)

As a result of this work, and much subsequent work done along similar lines, the Warlpiri Dictionary (now available through the computer dictionary interface Kirrkirr; see Manning et al. 2001) became a unique resource for studying the meaning of Warlpiri words and for understanding Warlpiri ways of thinking and Warlpiri culture in general.

NSM researchers have sometimes expressed reservations about the technical style of some Warlpiri Dictionary's definitions (Wierzbicka 1983; cf. also Goddard \& Thieberger (1997)), but have always emphasized their admiration for the wealth of linguistic detail and insight contained in it, including the folk definitions and commentary by Warlpiri consultants; see e.g. Wierzbicka (1983, 1990, 2008, 2009, 2014, 2015, in press), Goddard \& Wierzbicka (2014a: Chapter 4).

\section{References to 'parts' in Warlpiri Dictionary translations in the 'body domain'}

In exploring the material in the Warlpiri Dictionary pertaining to body parts, we used several approaches. We began by studying an early draft by Ken Hale and Mary Laughren (1982), 
titled 'Warlpiri Dictionary Project: Body part Domain: Preliminary remarks on the range of meanings and types of semantic relations in the body part domain in Warlpiri'. After this, we used the Advanced Search function of the Kirrkirr dictionary interface to look for English translations which included the word 'part', and studied the relevant Warlpiri sentences. We also located other entries on Warlpiri body-part terms in whose English translations the word 'part' did not appear. Using these methods, we compiled a collection consisting of 64 bodypart headwords. The entries of 35 of them contained one, or sometimes two, Warlpiri vernacular definitions or examples whose English translations include the word 'part'.

The source codes in the Dictionary indicate that almost all these vernacular definitions are the work of a single indigenous Warlpiri lexicographer, the late Paddy Patrick Jangala (henceforth: PPJ), who has been described by Nicholls (2013) as the "first professional Warlpiri linguist". PPJ worked on Warlpiri lexicography at Lajamanu in the mid-1980s, funded by the then Australian Institute of Aboriginal studies and other sources, and with the support of the Lajamanu-based SIL linguist Steve Swartz. PPJ was literate in Warlpiri and most of his definitions were composed in writing. PPJ's original intention was to produce a monolingual Lajamanu Warlpiri dictionary (Patrick 1984; Nash \& Patrick 1985; Simpson 1991: 438-439).

Having analyzed all the vernacular body-part definitions as best we could, we excluded from further consideration definitions where the concept 'part' appeared to be linked with a suffix rather than with a word, leaving this as a topic for future investigation. In choosing sentences to cite in the present paper, we were guided by the pragmatic criteria of clarity and brevity.

In the Warlpiri Dictionary material from the 'body domain', one sees numerous examples both in relation to human bodies and the bodies of animals. Notably, the word 'part' often appears in the translations of PPJ's vernacular definitions for words comparable to head, forehead, hip, buttocks, neck, midriff, and belly. To illustrate this, we start with just two examples (without interlinear glosses; bolding added).

lintirrpa (midriff)

Lintirrpa ngulaji yangka kuyu ngurlju, manu kuyu ramarra. Manu palka yapa ngakulykarla kanunju.

'Lintirrpa is the flank of an animal or the rib-cage. And that part of a person's body beneath the armpit.'

(2) ngarnturlurru (chest)

Ngarnturlurru ngulaji yangka rdukurduku kamparrujarra manu lampurnujarrawana, manu mangarli.

'Ngarnturlurru is the front part of the chest in the area of the breasts, and the heart.' 
On the face of it, such definitions would seem to suggest that Warlpiri speakers do talk about human bodies in terms of parts, but we would not want to assume that such English translations necessarily represent authentic Warlpiri meanings. If a lexicographer's goal, in this or any other bilingual dictionary, is simply to provide the closest "free translation", then idiomaticity in English will often override conceptual authenticity. To give an example from another domain of the Warlpiri Dictionary, one of the present authors has contended, in the context of discussion about visual semantics (Wierzbicka 2015, in press), that the presence of the word 'colour' in many English translations is a conceptual intrusion from English. For instance, consider the following Warlpiri text and its English translation.

The Warlpiri text

Kurdujungujungu, ngulaju ka nyina nyanjurrngu-rlangurla, yangka kujaka nyanjurrngu karri. [...] Walya nyanjurrngu-piya ka karrimi palka kurdujungujungu. Karlangu-parntapiya-kurlangu kajikanpa-jana nyanyi. Yangka ngulyangka-juku kajinpa nyanyi. Rurrpangka ka nyina kurdujungujungu.

The English translation

'Kurdujungujungu lives in the wet mud, like where there is muddy water. [...] It is the same colour as the earth and the mud. If you see it in its hole it looks like a scorpion. It lives in a hole'.

The English translation in the Warlpiri Dictionary uses two interpretative phrases, 'the same colour as ...' and 'looks like ...', but as the interlinear glosses given in (3a) and (3b) below (kindly provided by David Nash) make clear, only the second of these phrases has a counterpart in the Warlpiri original, i.e. there is no word corresponding to 'colour' in the original Warlpiri sentence (3a).

(3a) Walya nyanjurrngu-piya ka karri-mi palka kurdujungujungu. earth mud-like Pres stand- NonPast body freshwater.crab 'It is the same colour as the earth and the mud.'

\section{(3b) Karlanguparnta-piya-kurlangu} scorpion-like-Possessive

kajika-npa-jana nya-nyi 'If you see it in its hole it looks like a scorpion.'
see-NonPast

We are going to argue, however, that (unlike the use of the word colour), the use of the word 'part' in many translations in the Warlpiri Dictionary is entirely justified. Why? Consider, for example, sentence (1) cited earlier with the translation: 'Lintirrpa is ... that part of a person's body beneath the armpit.' If we suppose for a moment that this gloss is Anglocentric, how else could one portray the Warlpiri meaning through English words? There 
hardly seems an alternative to 'part'. But more to the point: is there a word in the Warlpiri text itself that could correspond, lexically, with 'part'? We think that there is, and to show what we mean, consider also the following, similar Warlpiri sentence. In (4), the free translation comes from the Dictionary while the interlinear glosses come from the present authors. [Note 2]

(4) $\operatorname{mimi}$ (forehead)

Mimi, ngalya, ngula-ji yangka jurru-ngka kamparru forehead forehead that-TOP part head-LOC front milpirimpiri-rla kankarlu... eyebrow-LOC above

'Mimi is that part of the head which is above the eyebrows...'

Two words which are central to our discussion are ngulaji (ngula-ji) and yangka, both bolded in the example above. Hale's (1974) Warlpiri-English Vocabulary describes them both as 'demonstratives'. The Warlpiri Dictionary entries for both provide a string of English counterparts, starting in each case with the word 'that'. As for $-j i /-j u$, it is glossed by the Dictionary as a 'topic enclitic' [Note 3]. In our interlinear glosses we will gloss ngulaji (or ngulaju) consistently as 'that-TOP', following Riemer (2005).

We argue below, however, that the word yangka has different meanings in different contexts, i.e. that it is polysemous, and that in a sentence like (4) it means 'part' (hence the interlinear gloss we have assigned it in this context). This proposal, we understand, may strike those familiar with linguistic descriptions of Warlpiri and related languages as unexpected, even jarring at first, because yangka is a closed-class item which is normally described as an "anaphoric demonstrative nominal" (as in the Warlpiri Dictionary itself) with an "evocative" effect (Hale 1974). To anticipate a little, we do not dispute that these are apposite linguistic descriptions for many contexts and uses of yangka, which is an extremely high-frequency word. Our case, however, is that a monosemy analysis for yangka is not viable and that in specific grammatical contexts it can also express two additional, distinct meanings.

\section{The three meanings of yangka: 'that, the one', 'like', 'part'}

Having studied numerous sentences with yangka in the Warlpiri Dictionary, and in other linguistic publications on Warlpiri, we have concluded that yangka can express three different meanings. In its first, and textually most frequent, meaning, descriptions such as "anaphoric nominal' and "evocative" are actually quite helpful. From a translational point of view yankga in this function can often be glossed as 'that' or as 'the one'. Following Simpson (1991) and 
Riemer (2005), we will use the interlinear glosses 'the.one' or 'that'. This use of yangka is illustrated below. [Note 4]

(5a) Pintapinta ngula-ji yangka paarr-pardi wita butterfly that-TOP the.one fly.NPST small pinkirrpa-wita-wangu-kurlu ...

wing-small-not-with

'Pintapinta is that small creature with big wings that flies...'

(5b) Warlu yangka-kurra-rlipa ya-ni!

fire that-to-1PL.INCL.SBJ go-NPST

'Let's go back to that (same) fire.'

In (5a), the phrase yangka paarr-pardi wita is translated as 'that small creature', and the interpretation of yangka as 'that' or 'the one' evidently makes sense. In (5b) too yangka is obviously best rendered into English as 'that': warlu yangka 'that fire'.

Careful examination of Warlpiri sentences has convinced us, however, that in particular contexts yangka can also express two additional meanings, namely, 'like (when)' and 'part'. These two additional meanings are illustrated in sentences (6) and (7), respectively (additional examples will follow).

$\begin{array}{llrrr}\text { Luwarni } & \text { ngula-ju } \text { yangka } & \text { kuja-ka } & \text { wati-ngki marda } \\ \text { 'luwarni' } & \text { that-TOP like } & \text { AUX.REL-NPST man-ERG maybe } \\ \text { luwa-rni } & \text { marlu karli-kirli-rli } & \text { manu ka luwa-rni } \\ \text { shoot-NPST } & \text { roo boomerang-PROP-ERG } & \text { or } & \text { AUX shoot-NPST } \\ \text { wardapi } & \text { watiya-kurlu-lu. } & & & \\ \text { goanna } & \text { stick-PROP-ERG } & & & \end{array}$

'Luwarni is like when a man maybe hits a kangaroo with a boomerang or hits a goanna with a stick.'

(7) kantumi (hip)

$\begin{array}{lllll}\text { Kantumi, } & \text { ngula } \text { kuyu } & \text { yangka } & \text { marlu. Kantumi } & \text { manu } \\ \text { hip } & \text { that animal part } & \text { kangaroo hip } & \text { or } \\ \text { yardipi } & \text { yi-ka-rlipa } & \text { ngarri-rni } & \\ \text { hip } & \text { AUX.COMP-PRS-1PL.INCL.SBJ call-NPST }\end{array}$

'Kantumi is what we call that part of the kangaroo which is its hip.'

In (6) the meaning of the verb luwarni is explained by likening it to familiar situations of someone striking or killing a kangaroo or a goanna, and, in this context, the Dictionary's translation of yangka as 'like (when)' makes perfect sense. In (7) the phrase yangka marlu is rendered in translation as 'part of the kangaroo', and this interpretation too makes sense. Interpreting yangka in (7) as either 'that one' or as 'like (when)' would not work. Clearly, this 
vernacular definition does not refer to 'that kangaroo' but to 'part of a kangaroo' (i.e. the hip), and nothing is being likened to anything else.

Each of the three senses of yangka that we have distinguished has its own combinatorial properties. Yangka $a_{1}$ as a demonstrative nominal is usually combined with some description, e.g. size, shape, or behaviour; yangka $a_{2}$ which means 'like (when)' is a clausal linker; and yangka $_{3}$ which means 'part' normally combines with a locus or locational expression that identifies the relevant whole and/or with the verb mardarni 'to have'. In sections 6 and 7, we will focus closely on yangka 3 'part', before returning to yangka, the clausal linker 'like (when)', in section 8 .

\section{Combinatorial properties of yangka 'part'}

Consider another sentence in which the combination yangka yapa is translated in the Dictionary as 'part of a person'. Once again, the interlinear glosses are our own.

(8) тији (tailbone)

Muju, yangka yapa purturlu-ngurlu kaninjarra-ngurlu

tailbone part person spine-from down-from

jaka-pirdi-ngirli ngula muju-ju mirntilyi-rla kanunju.

buttocks-near-from that tailbone-TOP anus-LOC under

'Muju is that part of a person which is down at the end of the spine towards the anus.'

The combination yangka yapa suggests that yangka in the sense 'part' can be juxtaposed to a noun indicating the 'whole' of which something (in this case, the tailbone) is a part. Expressions of this kind include the following ones (the glosses come from the Dictionary):

yangka yapa 'part of a person'

yangka marlu 'part of a kangaroo'

yangka kuyu 'part of an animal'

yangka milpa 'part of the eye'

yangka palka 'part of the body'

In example (9) the entry for yukuyuku 'shin, yangka 'part' appears in combination with, and adjacent to, palka 'body', though neither 'part' nor 'body' occur in the Dictionary's free translation. Our own translation of (9) would be: 'yukuyuku, that is the part Aboriginal people and white people have, the part of the body, from the knee down to above the foot'. In example (10) the entry for pawiyi 'spine', the two words yangka 'part' and palka 'body' again appear together, though not adjacent. [Note 5] 
(9) yukuyuku (shin)

$\begin{array}{llll}\begin{array}{l}\text { Yukuyuku, ngula-ji } \\ \text { shin }\end{array} \quad \text { that-TOP } & \text { part } & \text { Auja-ka-rlipa } & \text { yapa-ngku } \\ & \text { AUEL-PRS-1PL.INCL.SBJ } & \text { person-ERG }\end{array}$

manu kardiya-rlu marda-rni yangka palka mirdi-ngirli

or white.person-ERG have-NPST part body knee-from

kaninjarrakari (...) wirliya-rla kankarlu, ...

downwards foot-LOC above

'Yukuyuku is what both Aboriginal people and White people have from the knee down to above the feet ...'

(10) pawiyi (spine)

Pawiyi ngula-ji yangka kuja-ka-rlipa marda-rni,

spine that-TOP part AUX.REL-PRS-1PL.INCL.SBJ have-NPST

kakarda-rla purdangirli palka, manu yangka

back.of.the.neck-LOC down.below body or part

kuja-ka-rlipa marda-rni jimanta-jarra-rla palka.

AUX.REL-PRS-1PL.INCL.SBJ have-NPST shoulder-two-LOC body

'Pawiyi is the part of our body that is down below the back of the neck and between both our shoulders.'

Very occasionally, a combination of all three (yangka 'part', palka 'body' and yapa 'person, human') occurs, as in the following example (cited earlier without interlinear glossing).
lintirrpa (midriff)
Lintirrpa ngula-ji yangka kuyu ngurlju, manu kuyu
midriff that-TOP part animal midriff or animal
ramarra. Manu palka yapa ngakulyka-rla kanunju.
rib or body person armpit-LOC under
'Lintirrpa is the flank of an animal or the rib-cage. And that part of a person's body beneath the armpit.'

Our "literal" gloss for (11) would be: "lintirrpa, that is part of an animal, the midriff or animal's rib-cage; and [part] of a human body beneath the armpit'.

In many cases, admittedly, palka 'body' does not appear explicitly, especially in vernacular definitions which include a locational phrase identifying the position of the bodypart being defined with respect to another part, but in our view, there is nothing disturbing about this, and, indeed, it is only to be expected. When a Warlpiri lexicographer is undertaking the task of defining a number of body-part terms one after another (as PPJ reportedly did), it would be natural for him to omit the word palka 'body' most of the time, and keep only yangka 'part' and a word or expression specifying the location of that part within the body. Example (4) above, for mimi ('forehead'), is one such example. Example (12) below, for ngurlju (midriff) is another, and the same pattern appears in many subsequent examples. (Incidentally, it is worth noting that Wierzbicka (2007) argued that "location on the 
body" is to be expected as component body-part concepts across languages - part of the semantic template, in NSM parlance, for all or most body-part concepts.)

(12) Ngurlju (midriff)

Ngurlju ngula-ji yangka waku-jarra-rla kanunju, manu yangka

midriff that-TOP part arm-two-LOC under or part

ngakulyka-jarra-rla kanunju, manu yardipi-jarra-rla kankarlu

armpit-two-LOC under or hip-two-LOC above

ngurlju-ju, yangka kuja-ka-lu nguna-mi

midriff-TOP part AUX.REL-PRS-3PL.SBJ lie.be-NPST

ramarra-jarra ngurlju-ngka-ju.

rib-two midriff-LOC-TOP

'Ngurlju is that part (of the body) under the upper-arm, and below the armpits, and above the hips, where the ribs lie.'

Summing up so far, one characteristic aspect of these Warlpiri body-part definitions is that they combine the word yangka, in its 'part' sense, with a locational expression specifying where in the body that part is located. Now we will turn to a second salient characteristic of these vernacular definitions. More often than not, the body-parts are not simply said to be there in the body; rather, people (and often animals) are said to have those parts (somewhere in the body).

\section{A key combination: yangka and mardarni ('part' and 'have')}

In PPJ's vernacular definitions, yangka in the sense of 'part' is often combined with the verb mardarni 'have' [marda-rni have-NPST]. We have already seen an example in the definition of pawiyi 'spine' in (10), although in this case the Dictionary translation did not reflect the presence of mardarni in the Warlpiri sentence, i.e. there is no 'have' in the translation. In many other cases, however, mardarni is faithfully rendered as 'have' - usually, as 'we have' or as 'people have'. Here are two examples with 'part that we have' yangka kujakarlipa mardarni (in this expression, the 'we' meaning is conveyed by the $1 \mathrm{pl}$.inclusive pronominal clitic-rlipa on the auxiliary).

(13) luku (heel)

Luku ngulaji yangka kujakarlipa mardarni purdangirli wapanja-marnararla. Ngulanya luku, manu tariji.

' $L u k u$ is what we have behind to walk with. It is called luku and tari.'

(14) miyalu (abdomen, belly, stomach)

Miyalu, ngulaji yangka kujakarlipa mardarni nyampu rdukurdukurla kanunju, yangka mijilijilirla kulkurrirni yangka kujakarlipa ngula-kurraji ...

'Miyalu is what we have here under the chest with the navel in the middle of it ...' 
In our interpretation, (15) and (16) below both use the phrasing: "parts that we have [yangka...mardarni], Aboriginal people and white people'. Example (17) shows the expressions 'parts that women have [yangka...mardarni]' and 'that men have'.

(15) mirriji (shin)

Mirriji, ngulaji yangka kujakarlipa mardarni yapangku manu kardiyarlu wapanjakurlangu ...

'Mirriji is what both Aboriginal and European people have for walking with, ... .'

(16) ngarli (tendon above heel)

Ngarli, ngulaji yangka kujakarlipa yapangku manu kardiyarlu mardarni wirliyarla wapanjamarnarrarla, yangka lukungka kankarlu pulyku. Ngulanya ngarliji.

'Ngarli is what both Aboriginal people and European people have on the foot, the part that we walk with, it is the tendon above the ankle. That is the Achilles tendon.'

(17) ngapurlu (breast)

Ngapurlu ngulaji yangka kujakalu mardarni karntangku wirijarra jirrama kamparrujarra rdukurdukurla. Manu kujakalu mardarni watingki witajarra rdukurdukurla lampunujarraji.

"Ngapurlu are the two big things that women have on the front of their chests. And the two small breasts that men have on their chests.'

Finally, here are two examples with 'parts that birds (or cockatoos) have'.

(18) pinkirrpa (wing)

Pinkirrpa ngulaji yangka kujakalu mardarni jurlpungku waku-jarrarla, wita-witarlu manu wiri-wirirli, jurlpungku.

'Pinkirrpa are what birds have on both upper arms - small ones and big ones.'

(19) kakarda (nape)

Jirtawarnu, jirtawarnu ngulaji yangka kujaka mardarni kakardarla kakalyalyarlu.

'A crest, a crest is what the Major Mitchell cockatoo has at the base of its head.'

Overall, the most common form that the definitions of body-part terms take in the Warlpiri Dictionary includes five elements, as follows: (i) body-part word, (ii) the demonstrative word ngula with the topic suffix -ji, i.e. ngulaji, (iii) yangka, which we gloss as 'part', (iv) followed by the verb mardarni, (v) followed by a locative expression referring to an area in the body. For example:

tongue: that one, [it is] a part [of the body] we have in the mouth.

The word palka 'body' occurs in some definitions, but it is mostly omitted since the indigenous lexicographer is, presumably, composing several definitions one after another so it 
is understood that the context is about parts of the body. The verb mardarni 'have' is also not always present, but it frequently is and this is one of the formal features which can help distinguish yangka 'part' from yangka 'that, the one'.

Finally, it should be noted that the mardarni 'have' construction with yangka (e.g. 'those parts that we have') is usually not used when defining 'parts of parts'. Vernacular definitions for "sub-part" words, such as mimi 'forehead' (8), and kurlu 'pupil' (20) and jiwirnpa 'lower arm' (21) below, normally do not occur with the mardarni construction, but rather use the “yangka plus locational expression" construction described in section 6. [Note 6]

(20) kurlu (pupil)

Kurlu, kurlu ngula milpa. Kanunju. Palka kuja-ka-rlipa pupil pupil that eye under visible.thing AUX.REL-PRS-1PL.INCL.SBJ

milpa kanunju nyina-mi- kuja-ka-rlipa ngula-ngku nya-nyi

eye inside be.sit-NPST AUX.REL-PRS-1PL.INCL.SBJ that-ERG see

- ngula-mipa kurlu-ju yangka kanjunju. Milpa-juku-jala.

that-only pupil-TOP part under eye-still-actually

'The pupil, the pupil is the eye. Inside. What we have there inside the eye - that with which we see - it is only that part which is inside which is the pupil. But it is still the eye.'

(21) jiwirnpa (lower arm)

$\begin{array}{lccc}\text { Jiwirnpa, } & \text { jiwirnpa-ju } & \text { yangka-waku-rlangu-rla } & \text { nyampu } \\ \text { lower.arm } & \text { lower.arm-TOP part arm-for.example-LOC } & \text { this } \\ \text { kuja-ka } & \text { waku nguna-mi-rra rdaka-kirra. } & \\ \text { AUX.REL-PRS } & \text { arm } & \text { be.lie-NPST-away hand-towards } \\ \text { 'The forearm is that part of the arm which goes down to the hand.' }\end{array}$

\section{Yangka 'like (when)' as a clausal linker}

One of the many English words and phrases given in the Warlpiri Dictionary's entry for yangka is 'like (when)'. As mentioned, we believe that 'like (when)' is not only a possible translation equivalent (in some contexts), but is indeed one of yangka's possible meanings. This sense of yangka does not compete with the phrasal "LIKE suffix" -piya, but is rather an element that links with a following clause, like 'as' or 'like when' in English. For example:

(22) Yalyu, palkangka, ngulaju yangka yalyuju yapa-piyayi-jala ka karli. Yangka kurlardajangkarlanguju.

'Blood, in the body, that blood there flows as from humans. Like when it (i.e. kangaroo) has been speared for instance.'

Strictly speaking, this meaning of yangka is outside the scope of the present study, but it is necessary to pay some attention to it so that the polysemy of yangka does not prevent us from seeing its sense of 'part' clearly. Consider, for example, the following Warlpiri Dictionary 
definition for the verb pakarni 'hit', taken from Riemer's (2005) book on Warlpiri "impact and percussion" verbs. His interlinear gloss has yangka glossed as 'that', but the free translation uses 'like'.

\begin{tabular}{|c|c|c|c|c|}
\hline $\begin{array}{l}\text { Paka-rni } \\
\text { hit-NPST }\end{array}$ & $\begin{array}{l}\text { ngula-ji } \\
\text { that-TOP }\end{array}$ & $\begin{array}{l}\text { yangka } \\
\text { that }\end{array}$ & $\begin{array}{l}k u j a-k a \\
\text { AUX.REL-NPST }\end{array}$ & $\begin{array}{l}\text { karnta-ngku } \\
\text { woman-ERG }\end{array}$ \\
\hline
\end{tabular}

wati-ngki marda, kurdu-ngku marda, paka-rni nyiya-rlangu

man-ERG maybe child-ERG maybe hit-NPST something-for example

watiya-kurlurlu-rlu, jarntu marda, wardapi marda, manu yapa-kari

stick-PROP-ERG dog maybe goanna maybe or person-other

marda, kulu-ngku. Manu yangka kuja-ka paka-rni

maybe fight-ERG or that AUX.REL-NPST hit-NPST

warlkurru-rlu - wati-ngki marda, karnta-ngku marda, watiya -

axe-ERG man-ERG maybe woman-ERG maybe tree

warlu-ku.

firewood-DAT

'Pakarni is like when a woman, or a man or a child, hits something with a stick - a dog, or a goanna or another person in a fight. And it is also when a man or a woman chops a tree for firewood.' (Riemer 2005: 327)

Superficially, the sequence ngulaji yangka (or ngulaju yangka) in this and other verb definitions may seem identical to what we commonly see in the body-part definitions, and thus to undermine our interpretation of yangka as 'part'. A sceptic might suggest that this sequence is simply a definitional formula commonly used by indigenous Warlpiri lexicographers, and that since they use this formula for verbs as well as nouns, it has nothing to do with concept of 'part'. Closer inspection shows, however, that this hypothesis cannot be sustained. It is no accident that yangka corresponds to 'like' in the Dictionary's translation of the definition for a verb like pakarni 'hit', whereas it corresponds to 'part' in the translation of the definition of a noun like mimi 'forehead'. It seems to us that this is simply common sense: the translations wouldn't make sense the other way around.

We have examined a large number of the vernacular definitions cited in Riemer's (2005) book on Warlpiri verbs, and, as far as we can see, in verb definitions the sequence ngulaji yangka (or nguluju yangka) typically introduces a prototypical situation ('that's like when...' or 'that one, it's like when...'). Another example was presented as (6). It is repeated below for convenience. This time we have reproduced Riemer's (2005) interlinear glosses, to be consistent with example (23), but we contend that in both these sentences 'like (when)' is a more accurate gloss for yangka than 'that'.

$\begin{array}{llll}\text { Luwarni } & \text { ngula-ju } & \text { yangka } & k u j a-k a \\ \text { 'luwarni' } & \text { that-TOP } & \text { that } & \text { AUX.REL-NPST }\end{array}$




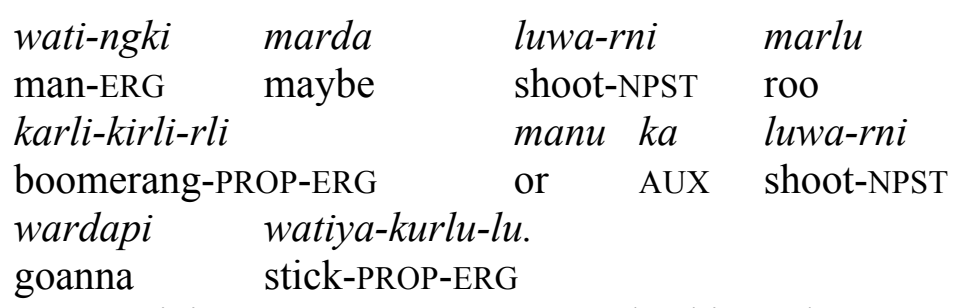

'Luwarni is like when a man maybe hits a kangaroo with a boomerang or hits a goanna with a stick.'

Furthermore, it is important to note that the sequence ngulaji yangka is not widely used in the definitions of nouns of all kinds. When we inspected fifty randomly selected entries in the Warlpiri Dictionary's 'fauna domain' we found that only two of them used ngulaji yangka. Of these, one was clearly used in the sense of 'like' and the other in the sense of 'that, the one'. By contrast, in our collection of 64 body-part entries as many as 19 include the sequence ngulaji yangka, with yangka almost always indicating a particular part of the body. A similar sampling exercise with words from the 'manufacture domain' produced parallel results, i.e. in most of these definitions an opening yangka had the sense either of 'like (when)' or 'that, the one'.

In short, while the sequence ngulaji yangka can indeed be found in many parts of the Warlpiri Dictionary, its use in the definitions of body-parts is sui generis, and supports the hypothesis of 'part' as a distinct meaning of yangka.

\section{Discussion: paraphrase, polysemy and allolexy}

In sections $9-12$, we would like to widen the discussion to clarify the general NSM position on polysemy and its relationship to paraphrasability and then to consider some data from other languages. It is of course a crucial aspect of our case that the Warlpiri exponent of PART is polysemous. Lest it be thought we are indulging in some special pleading, we would point out that the French exponent is also polysemous (because French partie, as in parties $d u$ corps 'parts of the body', has also other meanings, such as 'party' as in 'political party'), and so indeed is the English word part, as we will discuss more fully in section 11 .

The hallmark of the NSM approach to semantics is paraphrase: to state the meaning of a word is to say the same thing in other words. In this, NSM semantics follows the lexicographic tradition, while at the same time following what we see as the "common sense" approach. Paraphrase can be used as a test to establish the equivalence or non-equivalence of meanings of words. The key criterion is not simply paraphrasability, however, but more precisely, paraphrasability without circularity. In this respect, NSM semantics makes a radical break with traditional lexicography. 
To make this more concrete, consider how the Collins Cobuild English Language Dictionary (1991) defines part via piece, piece via part and bit, and bit via piece and part, as follows:

part - a part of something is one of the pieces that make up an object.

piece - a piece is a bit or part of something that has been broken off, or cut off.

bit - in informal English, a bit of something is also a small piece of it

bit - in fairly informal English, you can refer to a particular part of something [...] as a particular bit of it.

At first sight it may seem that the meanings of all three words - part, piece, and bit - can be paraphrased. In effect, however, the dictionary implicitly admits that they cannot all be paraphrased, because its attempts to paraphrase them all lead to circularity.

It is not always obvious whether two words or phrases mean exactly the same or not. NSM semantics has developed techniques for establishing it in any given case. Using these techniques one can show, for example, that body in the phrase 'mind and body' means the same as body in the phrase 'body and soul', but not the same as body in the phrase 'head and body'. In a nutshell, it can be shown through paraphrases which do not lead to circularity (cf. Goddard 2000; Goddard \& Wierzbicka 2014b: 94-106).

The same approach applies to establishing the sameness of meaning between two different words which can both be exponents of the same prime, i.e. allolexes. For example, it can be shown that the Latin words bonum and bona mean exactly the same, despite the former being grammatically 'neuter', and the latter, 'feminine'. Likewise, bonum and bona (as well as bonus, 'masculine') can be shown to mean exactly the same as the morphologically invariable English word good: we cannot find any paraphrasable differences between these words and so we must accept that they mean exactly the same.

\section{A Papuan perspective: polysemy and allolexy of PART in Koromu}

Both polysemy and allolexy are common in natural languages - and normally, they do not seem to create any serious problems for interpersonal understanding. We quote below Carol Priestley's (in press) reflections on polysemy and allolexy in the Papuan language Koromu, where, as in many Papuan languages, the same form can mean either 'body' or 'skin'.

Many linguists probably find, as I have done, that when speaking a language polysemy is not an issue until one has to represent it or discuss it as a linguist. [...]

Just as English speakers identify the sense of body that is intended or tolerate the imprecision, Koromu speakers tolerate the ambiguity of mete 'body/skin' or identify the particular sense from the context and other semantic clues. 
Thus, the polysemy of mete (1. body, 2. skin) does not prevent Koromu speakers from discerning the prime sense (BODY) in contexts like 'parts of the body'; and neither does the allolexy of the Koromu exponents of PART prevent them from discerning its sense as a prime. As Priestley explains:

Depending on context, a prime can also have multiple exponents, or allolexes, for one meaning. For example, English has the allolexes OTHER and ELSE as in other things and in something else, while Koromu has multiple exponents of PART, namely, MO, ASAO and $-N E$. [...] As the head of a noun phrase in a verbal possessive clause PART is realized as $M O$.

(3) Mete mо пири пири mеn-a.

body part many many have-3SG

'The body has many parts.'

In an expression like 'part of the body' PART is realized as asao, a term that can be used elsewhere with the sense 'some'.

(4) Ami mete asao.

eyes body part

'The eyes are part of the body.' (Priestley In press)

As Priestley's (in press) data and analysis show convincingly, neither polysemy nor allolexy prevent clear rendering of the concept identifiable in English as part: both mo and asao are valid exponents of this concept in Koromu. True, both are polysemous (mo: 1. THIS, 2. PART; asao: 1. SOME, 2. PART), but in particular contexts each of them can do its job clearly and effectively as an exponent of PART.

What is particularly interesting in the present context is that one of the main exponents of PART in Koromu is a demonstrative, somewhat like the situation in Warlpiri. Speaking somewhat fancifully, it is as if to convey the thought 'the body has many parts' Koromu speakers were saying 'the body has many this-es'. For English speakers, the only way to make sense of the Koromu sentence is to assume that "has many this-es" means the same as 'has many parts'. To assume otherwise would be to exoticize Koromu speakers and to posit an unbridgeable gulf between them and speakers of English, without any necessity (cf. Keesing 1994). The same applies to comparisons between English and Warlpiri.

So the point is not that there is a "dedicated expression" for PART in every language, but that in every language people can conceptualise the body as having parts and have some equivalent expressions for talking about it in terms of parts. Evidently, from this point of view, Warlpiri yangka (yangka $)_{3}$ is as serviceable as English part (part $)_{1}$. At this point, it will useful to consider more carefully the polysemy of the English word part. 


\section{Polysemy of English part: distinguishing PARTS and SOME}

The English word part is multiply polysemous. Somewhat improbably, the Collins Cobuild Dictionary distinguishes 32 numbered meanings (28 of them nominal). Careful semantic analysis would presumably lead to a radical reduction in this number, but there is no doubt that part is indeed polysemous. Above all, we want to highlight here the fact that English part can be an exponent of two different semantic primes: PART and SOME. For example, in a phrase like 'a small part of the money' or 'part of the grain (went bad)', part doesn't stand for PART (as in 'one of the parts') but for SOME (as in 'some of it, not much').

The two primes in question, i.e. PARTS and SOME, have a certain affinity, and the pattern of polysemy evident in the phrases 'two long parts' and 'two equal parts' appears to recur in many languages - not only European (e.g. French, German, Polish, Russian), but also, as we have seen, in totally unrelated ones such as Koromu. It is not, however, a pattern shared by Warlpiri, where the concept SOME (OF) is expressed, above all, with the word ngalyakari, as in the following examples:

(25) Wurlkumanu-wurlkumanulpalu yanurra ngalyakari yakajirriki, yarlaku. 'Some of the old women went off to get Bush Onions and yams.'

(26) Ngalyakari-jikilparnalu pita-ngarnu - panungkuja ngarra yapangkuju - nganimparluju. 'We only ate some of them, as there were really so many of us people.'

(27) Pirda-manulu-nganpa pirdijirrirli. Pajirninjarla, pajirninjarla kalalu-nganpa yungu. Rdilyki-pungu, rdilyki-pungu. Bread-piya. Ngalyakari kalalu-jana yukanti-yukantiki yirrarnu - kurduku. Miyalu-juntulku-parra. Watiki kalalu-jana yirrarnu ngalyakari. Manu karntaku ...

'They would fill us up with seedcake. They would break it up into pieces and give it to us. (They would) break it up like bread. They would put one lot for the small children to fill their tummies. They would set out another pile for the men, and a separate one for the women ...'

(28) Kurlarda-jana yangka yali ngalyakari manurra, murlarrily-murlarrilyparra rdipija. 'He picked up some of the spears and set off with them in a bundle swinging to and fro in his hand.'

The lack of correspondence in the patterns of polysemy between English (and other European languages), on the one hand, and Warlpiri (and other Australian languages), on the other hand, may have contributed to the impression that Warlpiri lacks expressions for semantic prime PART.

Before leaving the subject of PART vs. SOME, we would like to acknowledge that the boundary between the two has not always been drawn clearly in NSM literature. For example, in Wierzbicka's (2002) chapter on Polish in Meaning and Universal Grammar, the section 
entitled 'Taxonomy and partonomy' included two sentences, (246a) and (246b), only one of which (246a) would be regarded today as including the prime PART. Wierzbicka (2002: 145) wrote as follows:

The Polish word for KIND is rodzaj, and the word for PART is częśc. While rodzaj seems unproblematic, czesśc raises the question of the relation between phrases such as (246a) and (246b) below:

$\begin{array}{llll}\text { (246) (a) Śledziona to jest } & \text { czesść } & \text { ciała. } \\ & \text { spleen.NOM COP be.3SG.PRES part.NOM } & \text { body.GEN } \\ \text { 'The spleen is a part of the body.' } & \\ \text { (b) Częśc w wody sie } & \text { wylała. } & \\ \text { part.NOM water.GEN REFL spill.3SG.PAST.PERF } \\ \text { 'Part of the water spilled.' }\end{array}$

Wierzbicka's discussion of these two sentences was inconclusive:

In English, one can also say Some of the water spilled but in Polish, no such option is available. Is część polysemous or does it carry the same meaning in (a) and (b) above? The question, which bears on our understanding of the prime PART, requires further investigation. (Wierzbicka 2002: vol. 2, p. 145)

Fifteen years on, much more is known about the primes PART (or YANGKA) and SOME (or NGALYAKARI) and it can be confidently affirmed that only sentence (246a) includes the former (whereas (246b) includes the latter). It must be admitted, however, that the lack of clarity about this point and a measure of confusion between PART and SOME in some NSM publications (e.g. Wierzbicka 2009; Goddard 2011: Chapter 9) may have contributed to the misunderstandings surrounding the universal status of PART.

\section{Patterns of polysemy in the exponents of semantic primes}

As noted earlier, the Warlpiri 'part/that' polysemy is analogous to what we have seen in Koromu. This leads us to the hypothesis that 'part' and 'this/that' (so to speak) may be a second polysemic pattern involving PART which recurs in many languages, in addition to the 'part of'/'thing (of)' pattern identified in earlier NSM literature and discussed in section 2. As Wierzbicka (2007: 27) observed in her paper 'Bodies and their parts':

This particular NSM finding - that in many languages the word for 'thing' or 'something' can function as an exponent of part - is in fact utilized (though not sourced) in the Special Issue's [Majid et al. eds. 2006] "Elicitation Guide", where the contributors are told that, e.g., a meaning expressed in English as the arms are parts of the body may be expressed in some languages by an idiomatic construction along the following lines: "The arm is the thing of the person" (p. 156). 
The current finding that in some languages a word like 'this' or 'that', or similar, can be an exponent of PART could be also utilized as a hint for fieldworkers investigating the vocabulary structure of their field languages: "if 'the arm is the thing of the body (or: of the person)' doesn't work, you may try 'the arm is this (or: that) of the body (or: of the person)".

Such recurrent polysemies, linking PART with THIS, or with THING, or with SOME, are of course very interesting in themselves and raise the question: "Why is it so?" This is indeed an thought-provoking question, but it needs to be seen within a wider context. It is well established in the cross-linguistic NSM literature (e.g. Goddard \& Wierzbicka 1994, 2002; Goddard 2008, Goddard 2011) that primes often share lexical exponents in ways which are not entirely unpredictable, without being fully predictable either. For example, in a number of languages DO and HAPPEN share the same lexical exponents (in different grammatical frames); and the same applies DO and SAY, FEEL and HEAR, HEAR and THINK, SOMEONE and PEOPLE, BODY and SOMEONE, HERE and NOW, CAN and MAYBE, among other examples. Partial morphological overlaps between certain primes are also common, both for the examples just mentioned, and also for other pairs such as SAY and WORDS. In each case, one senses that the members of the pair have "something in common", so to speak. On the other hand, we have not come across similar patterns of polysemy or morphological overlap which involve primes which are intuitively completely unrelated to one another, for example, KNOW and LIVE, WORDS and BODY, HERE and BEFORE, SAY and DIE, Or PEOPLE and FAR.

But to say that primes which often share lexical exponents usually have "something in common" does not mean that they share a semantic component which can be identified through a paraphrase. On the contrary, semantic primes cannot be paraphrased so this possibility does not arise; hence the term used in the NSM literature to designate this phenomenon: non-compositional polysemy (Goddard \& Wierzbicka 1994). For example, two properties that DO and HAPPEN have in common is that both require an (explicit or implicit) reference to time ('when did it happen?', 'when did he do it?') and that both allow a description of "manner" (e.g. 'it happened like this: ...', 'he/she did it like this: ....'). KNOW and LIVE, by contrast, do not have such properties. To give another example, one thing that SOMEONE and PEOPLE have in common that both can combine with WANT, KNOW and THINK, as "personal subjects", so to speak. HERE, NOW and THIS all have a special link with I (ME) (for example, one can say, in any language, 'I am here now'). All such recurring patterns of polysemy between exponents of primes are worth investigating [Note 7], and they all suggest some conceptual links, but not links that can be shown through paraphrases. The recurring 
patterns of polysemy involving PART are certainly interesting, but perhaps no more so than recurring patterns of polysemy involving exponents of other primes. In any case, it is outside the scope of this paper to pursue this problem further here.

\section{Back to Warlpiri: can Warlpiri be its own metalanguage?}

The material in the Warlpiri Dictionary bearing on the question of body-parts is rich and complex and in this paper we have only touched on it selectively. Two things, however, seem clear to us: first, Warlpiri speakers can speak and think about human bodies as having parts and they do have a word for PART (as well as a word for BODY) at their disposal; and second, Warlpiri is consistent with the conclusion reached in Wierzbicka (2007: 53): "semantic explorations undertaken in the NSM framework confirm the fundamental role of the notion 'part of the body' as a universal organizing principle in all ethnoanatomies". The latter conclusion applies not only to describing the lexicon of body-part meanings, stricto sensu, but also to their patterns of extension.

In her article 'Remarks on the semantics of body part terminology in Warlpiri', Laughren (1984) states a number of generalizations about extended uses of Warlpiri body-part terms, formulating her generalisations in terms of 'part'. For example, she writes:

Our investigations have led us to posit the human body as the primary domain for body part terminology. (...) By analogy, the "equivalent" part of a non-human body is designated by the same term that refers to a "human" body part. Similarly, a part of a non-animate entity, can be designated by a term which in its stereotypical meaning designates a part of a human body. Thus the semantic relation of analogy involves a change of domain: from human to non-human, from being to non-being. (Laughren 1984: 2)

Laughren illustrates these generalizations, inter alia, with the following examples:

JURRU head of being $\rightarrow$ rounded end part of entity: rounded end of spear-thrower JURRU head of being $\rightarrow$ uppermost part of non-being: upper section of boomerang (short end not held in hand), top section of native bee hive MULYU nose, snout, beak of beings $\rightarrow$ foremost part of entity: "front" of car (...) JAKA buttocks of human $\rightarrow$ hindmost part of some non-being: "back" or rear end of vehicle, pointed "ends" of a coolimon, shield, etc. (...)

MILPA eye of being $\rightarrow$ small round parts of entity: seeds inside pod, drops of rain water, head-lights of vehicle (1984: 2-3)

This description is clearly predicated on the assumption that in their primary meanings, the words jurru 'head', mulyu 'nose', jaka 'buttocks' and milpa 'eye', all include the semantic 
element 'part'. (Cf. Hale (1981) for arguments that the concept of 'part' plays an important role in Warlpiri grammar, in various 'part-whole' constructions.) According to Laughren, such generalizations about semantic relations in Warlpiri are part of the native speakers' linguistic competence:

It is our belief that the nature of the semantic relations between the different meanings of a given lexical item, the natural classes into which those meanings fall, as well as the semantic relation which exists between items with common meanings, [...] should be clearly derivable from the dictionary entries of the terms themselves. Such knowledge is surely borne out not only by an internal analysis of the lexicon such as we have presented here, but by the way in which speakers extend body part terms to designate new referents. For example, parts of a new domain, e.g. motorcars [...], are and will be spontaneously named according to the principles described here. (Laughren 1984: 8-9)

All this is entirely convincing. The question that arises, however, is: can such knowledge be stated in Warlpiri itself? Or can it only be stated in languages like English? We earlier quoted Casagrande \& Hale's (1967) remark that “every language must thus serve in some degree as its own metalanguage". Generally speaking, to say that a word used for a part of the body of a person can be also used for a part of the body of an animal or for a part of a car (if it is in the same place in the car), one needs a word for 'part'. As we see it, there is no reason to assume that such generalizations cannot not be made in Warlpiri.

For example, one could state the rationale for extending the word for 'head' to animals, as follows. (The Warlpiri version would use the yangka + mardarni "have parts" locution discussed in section 7.)

people can think about many animals like this:

"this animal's body has many parts like parts of a person's body one is like a person's head"

Similarly, considering the use of various body-part words in relation to cars (milpa 'eyes' for headlights, mulyu 'nose, snout' for the front of a car, jaka 'buttocks' for the rear end), one could posit that from a Warlpiri point of view 'people can think about cars like this: 'they have many parts like parts of a person's body'. Or possibly, 'they have many parts like parts of an animal's body': the exact basis of the extension is not clear to us at this point.

In any case, our main point is that the Warlpiri language has all the necessary words and phrases to articulate the principles underlying Warlpiri semantic competence in this area, i.e. words for 'person' (yapa), 'part' (yangka), 'body' (palka), 'animal/creature' (kuyu, in one its 
meanings), and phrases like 'have parts', 'like a person's head', and so on. Speaking more generally, we would like to express confidence in the capacity of Warlpiri to function as its own semantic metalanguage in all domains of cultural knowledge, and indeed to extend this confidence to other indigenous languages of the world.

\section{Broader perspectives}

We would like to close with two final remarks on broader issues of translation and language documentation. First, it is heartening to note that there are signs of growing interest in Australia in indigenous stories, indigenous perspectives, indigenous voices. Yet, as we see it, it is important that English renditions of Aboriginal stories are formulated in crosstranslatable English in order to preserve authentic indigenous meanings, as far as possible, and to minimise intrusions from Anglo, or European, ways of thinking. For example, Aboriginal words that mean 'see', 'do' and 'say' should be translated as such, and not, for example, as 'witness', 'perform', or 'declare'. Highly English-specific words such as 'actually', 'reason' and 'fact' should be avoided. As we see it, this Anglicising style of translation poses a much greater threat to conceptual authenticity than translating a polysemous word like yangka as 'part', e.g. when speaking about parts of the body.

Second, in relation to language documentation, we see it as important to pay particular attention to capturing culture-specific concepts, especially the meanings of cultural key words, in Australian languages and in other indigenous languages around the world. This is a difficult task and it requires careful attention to the metalanguage of the description (Goddard \& Wierzbicka 2014b). In particular, it requires us to avoid using highly English-specific words to gloss indigenous meanings, and to strive instead to portray them using crosstranslatable words and phrasings, i.e. words and phrasings which have equivalents in the indigenous language itself. 


\section{Acknowledgements}

Research assistant Helen Bromhead made substantial intellectual contributions to this study, as well as managing complex searches in the Warlpiri Dictionary and other sources. We are grateful to three anonymous reviewers for AJL. Their comments have helped improve the argumentation and, in some cases, saved us from some errors of interpretation. Needless to say, responsibility for the remaining faults lies with the authors.

\section{Notes}

1) To quote Annabelle Mooney's (2014) recent book Human Rights and the Body: Hidden in full sight: "The body is our base, our mode of being in the world, it places us in space, it is the origin of meaning and experience. It is our zero institution." (pp. 89-90)

2) For reasons of space and clarity it would be counter-productive to provide interlinear glosses for every Warlpiri sentence cited, but we have provided them wherever we thought they were really needed. The following is a list of the abbreviations used (note, though, that in quoted examples the interlinear glosses follow the original text):

1PL.INCL.SBJ first person plural inclusive subject clitic; 2 sgSubj second person singular subject clitic; 3 third person; 3PlObj third person plural object clitic; 3PL.SBJ third person plural subject clitic; AUX.REL auxiliary relative; COP copula; DAT dative; ERG ergative; GEN genitive; GIV given; IMP imperative; INF infinitive; LOC locative; NOM nominative; NMZ nominalization; NPST nonpast; PRS present; PROP proprietive; PURP purposive; RDP reduplication; REFL reflexive; SG singular; TOP topic.

The glossing was carried out by looking up Warlpiri words and morphemes in the Warlpiri Dictionary itself and in other sources including Hale (1974), Laughren \& Hoogenraad (1996), Nash (1986a, Nash 1986b), Riemer (2005), Simpson (1991), and Swartz (n.d.). For some suffixes and enclitics, we have chosen to use an English label rather than a Latinate one (e.g. -ngurlu 'from' rather than EL, for elative), while for others, we have used the conventional label (e.g. -rla/-ngka LOC, locative). For the auxiliary cluster, we have followed Riemer (2005) for elements such the auxiliary relative kuja (AUX.REL), but we have followed David Nash in glossing $k a$ as marking present tense (as opposed to Riemer 2005 who glosses it as nonpast). In the interests of clarity, we have not used the clusters of numbers (e.g. 1, 2, 3, 12, 11, 22) in glossing Warlpiri pronominal clitics but more transparent glosses such as 1PL.INCL.SBJ.

Interlinear glossing can be an invidious exercise in that one is forced to commit to morphological, syntactic and semantic interpretations in a highly constrained space, sometimes when one is focussed on one particular aspect of a language, and is less concerned with others. As stated in the 'The Leipzig Glossing Rules', "glossing is rarely a complete morphological description, and it should be kept in mind that its purpose is not to state an analysis, but to give some further possibly relevant information on the structure of a text or an example, beyond the idiomatic translation" (Comrie et al. 2008). Given that interlinear glosses should be consistent (Lehmann 2004: 11), variation in glossing has been kept to a minimum, though occasionally polysemous words are glossed according to the relevant sense in the given context. 
3) The 'topic enclitic' $-j i$ has the basic form $-j i$ in the Hansen River, Lajamanu, and Willowra varieties of Warlpiri, and $-j u$ in the Yuendemu variety. Additionally, the vowel in the enclitic is subject to vowel harmony, with slightly different rules in different dialects (Laughren, Hale \& Warlpiri Lexicography Group 2006; Nash 1986a: 56). Some sources also state that this enclitic is used "to lengthen a word for stylistic euphony" (Hale 1973: 15; see also Nash 1986a: 56; Simpson 1991: 436).

4) Although we sometimes use 'that' as a translation equivalent or short gloss for yangka, it is important to bear in mind that its meaning is not exactly the same as the English word that, because the latter does not encode any "assumed to be obvious or known" aspect. The Warlpiri Dictionary gives yangka a series of glosses, as follows: "yangka English: that, those, that same, the one, the one in question, the aforementioned, like, you know the one. Definition: anaphoric demonstrative nominal which refers to the established topic of the utterance including yangka". PPJ's vernacular definition (evidently for the "evocative" yangka) is as follows: Yangka, ngulaji yangka kujaka yapa jinta-juku jurrku-juku yanirni warrarda ngurra-kurra jinta-kurra, kujakarla warrarda yanirni jurrku-juku karntaku waninja-warnuku - wati. Yangka jinta-juku yapakariwangu. [Source: PPJ 10/87] 'Yangka is like when the same person, the very same one always comes to the same camp, as a man comes all the time to see his girlfriend. It is the same one, not another one.' Hale's (1974) dictionary describes yangka as follows 'the, that evocative (i.e., the one you know about)'.

It is not necessary for the purpose of this paper to propose an NSM analysis for the "evocative" meaning (or meanings) of yangka. We would like to remark though, that although descriptive labels like 'evocative' (and, for that matter, 'demonstrative') may be useful at some stage of linguistic analysis, they cannot be regarded as statements of meaning, in the NSM sense, because they are not cross-translatable paraphrases, substitutable in context.

5) A reviewer suggests that in (10) the word palka does not mean 'body', but instead carries a second meaning, for which the Dictionary gives the definition "physical presence of something" (and lists English equivalents: presence, present, in person, actually, really, something). PPJ's definition of this second sense of palka was: "Palka is anything that is visible out in the open, not in thick grass. It is when somebody can see it visible, not in the undergrowth or hidden down in the bushes." Two sentences illustrating palka in this sense are translated as 'The water from the recent rains lying there in the open country is visible [palka] in the distance' and 'He points out to someone else a kangaroo which is there in the distance which he can actually see [ngula ka nyanyi palkalku]'. It seems clear to us, however, this is not how palka is used in Warlpiri sentence defining the word pawiyi 'shoulder', which refers to a constant, not transient, part of the human body. Perhaps recognising this, the reviewer also proposes that "in combination with the verb mardarni 'have, hold', palka could be glossed as "actually" - 'what we have (present)/what we actually have'". We see no real evidence in support of this apparently ad hoc suggestion. (We would also object in principle to the assumption that a highly English-specific word, such as 'actually', is likely to be a suitable gloss for a Warlpiri meaning, cf. section 14).

6) Since so many of the vernacular definitions originate with PPJ, it is possible that other Warlpiri speakers may have alternative definitional strategies, or different preferences so far as the balance between the two yangka constructions described in sections 6 and 7 are concerned. Nevertheless, the scope and volume of PPJ's contribution as the 
founding father of indigenous Warlpiri lexicography surely militate against any impulse to dismiss his oeuvre as the product of only one man.

7) Non-compositional affinities also exist between between primes which are in antonymic relationships. For example, no one can doubt that GOOD has a conceptual affinity with BAD, as does BIG with SMALL, yet none of these words can be decomposed. In particular, BAD cannot be equated with 'not good', or SMALL with 'not big'. Such affinities can also be reflected in recurring polysemies; for example, in some languages, e.g. Cantonese, the exponent of BAD may look like a combination of 'not' and 'good' [not.good]. Evidence indicates, however, that in all such languages one can also convey the meaning 'very bad', different from 'not very good'. Ultimately, semantic analysis must rely on semantic evidence (which includes evidence from combinability). If meaning and form point in different directions, it is the meaning that decides, not the form. 


\section{APPENDIX 1}

The provisional table below was informed by searches of the Warlpiri Dictionary, and by consulting sources such as Bittner \& Hale (1995), Evans \& Wilkins (2000), Hale (1974) and Laughren (1992). Verbs are given in present tense form. The authors are aware that Warlpiri is composed of a number of different dialects, and that some exponents in different dialects may vary. The provisional table may include some inconsistencies in this regard.

Provisional Table of Warlpiri Semantic Primes, with English equivalents.

\begin{tabular}{|c|c|}
\hline NGAJU, NYUNTU, NGANA, NYIYA, YAPA, PALKA & \multirow[t]{2}{*}{ substantives } \\
\hline I, YOU, SOMEONE, SOMETHING THING, PEOPLE, BODY & \\
\hline NYIYAKARI-NYIYAKARI, YANGKA YANGKA MARDARNI & \multirow[t]{2}{*}{ relational substantives } \\
\hline KINDS, PART HAVE PARTS & \\
\hline NYAMPU, -MIRNIMIRNI, -KARI & \multirow[t]{2}{*}{ determiners } \\
\hline THIS, THE SAME, OTHER ELSE & \\
\hline $\begin{array}{l}\text { JINTA, JIRRAMA, NGALYAKARI, MUKU, PANU, NGUKARA- } \\
\text { WANGU }\end{array}$ & \multirow[t]{2}{*}{ quantifiers } \\
\hline ONE, TWO, SOME, ALL, MUCH MANY, LITTLE FEW & \\
\hline NGURRJU, MAJU & \multirow[t]{2}{*}{ evaluators } \\
\hline GOOD, BAD & \\
\hline WIRI, WITA & \multirow[t]{2}{*}{ descriptors } \\
\hline BIG, SMALL & \\
\hline $\begin{array}{l}\text { PINA, MIYALU WANGKAMI, NGAMPURRPA, NGAMPURRPA- } \\
\text { WANGU, PURDA-NYANYI NYANU, NYANYI, PURDA-NYANYI }\end{array}$ & \multirow[t]{2}{*}{ mental predicates } \\
\hline KNOW, THINK, WANT, DON'T WANT, FEEL, SEE, HEAR & \\
\hline WANGKAMI, YIMI, JUNGA & \multirow[t]{2}{*}{ speech } \\
\hline SAY, WORDS, TRUE & \\
\hline JARRIMI, JARRIMI, YIRIRRIMI & \multirow{2}{*}{$\begin{array}{r}\text { actions, events, } \\
\text { movement }\end{array}$} \\
\hline DO, HAPPEN, MOVE & \\
\hline NYINAMI, NYINAMI, NYIYA & \multirow{2}{*}{$\begin{array}{r}\text { location, existence, } \\
\text { specification }\end{array}$} \\
\hline BE (SOMEWHERE), THERE IS, BE (SOMEONE/SOMETHING) & \\
\hline NGAJUNYANGU & \multirow[t]{2}{*}{ possession } \\
\hline (IS) MINE & \\
\hline JIPI-PARDIMI, PALIMI & \multirow[t]{2}{*}{ life and death } \\
\hline LIVE, DIE & \\
\hline $\begin{array}{l}\text { JAPAKU-(?), JALANGU, -WIYI, -LKU, TARNNGA, } \\
\text { JALANGU-PARNTA, ??, MAJUNGURLU }\end{array}$ & \multirow[t]{2}{*}{ time } \\
\hline $\begin{array}{l}\text { TIME WHEN, NOW, BEFORE, AFTER, A LONG TIME, } \\
\text { A SHORT TIME, FOR SOME TIME, MOMENT }\end{array}$ & \\
\hline $\begin{array}{l}\text { NGURRA(?), NYAMPU, KANKARLU, KANINJARNI, WURNTURU, } \\
\text { WARRIRI, -NGINTI, NGAWIRA, WILILIKI }\end{array}$ & \multirow[t]{2}{*}{ place } \\
\hline PLACE WHERE, HERE, ABOVE, BELOW, FAR, NEAR, SIDE, INSIDE, TOUCH & \\
\hline KULA, MARDA, KALA-KA, YINGA -JANGKA, KAJI-LPA & \multirow[t]{2}{*}{ logical concepts } \\
\hline NOT, MAYBE, CAN, BECAUSE, IF & \\
\hline -NYAYIRNI, YARDA & \multirow[t]{2}{*}{ intensifier, augmentor } \\
\hline VERY, MORE & \\
\hline -PIYA YANGKA & \multirow[t]{2}{*}{ similarity } \\
\hline LIKE AS & \\
\hline
\end{tabular}

- Exponents of primes may be words, bound morphemes, or phrasemes. For example, Warlpiri -PIYA (LIKE) is a suffix and English A SHORT TIME is a phraseme. - Exponents of primes may be formally complex. For example, in Warlpiri PURDA-NYANYI (HEAR) and NYANYI (SEE) share some morphological elements, as do SOMEONE and SOMETHING in English. - Two primes can share the same lexical exponent, with different syntactic properties, e.g. in Warlpiri, with NYAMPU (THIS) and NYAMPU (HERE), PURDA-NYANYI (HEAR) and PURDA-NYANYI NYANU (FEEL) - A prime may have more than one exponent. For example, in English I and ME are two different variants (allolexes) of the same prime, and so are OTHER and ELSE.

- Each prime has well-specified syntactic (combinatorial) properties. 


\section{References}

Andersen ES 1978 'Lexical universals of body-part terminology' in JH Greenberg (ed) Universals of Human Language Volume 3: Word Structure Stanford: Stanford University Press. pp. 335-368.

Bittner M \& K Hale 1995 'Remarks on definiteness in Warlpiri' in E Bach, E Jelinek, A Kratzer \& BBH Partee (eds) Quantification in Natural Languages Dordrecht: Kluwer. pp. 81-105.

Brown CH 1976 'General principles of human anatomical partonomy and speculations on the growth of partonomic nomenclature' American Ethnologist 3: 400-424.

Bugenhagen B 1994 'The exponents of semantic primitives in Mangap-Mbula' in C Goddard \& A Wierzbicka (eds) Semantic and Lexical Universals: theory and empirical findings. Amsterdam: John Benjamins. pp. 87-108.

Casagrande JB \& K Hale 1967 'Semantic relationships in Papago folk-definitions' in DH Hymes \& WE Bittle (eds) Studies in Southwestern Ethnolinguistics: meaning and history in the languages of the American southwest The Hague: Mouton. pp. 165-193.

Collins Cobuild English Language Dictionary 1991 London: HarperCollins.

Comrie B, M Haspelmath \& B Bickel 2008 'The Leipzig Glossing Rules: Conventions for interlinear morpheme-by-morpheme glosses'.

https://www.eva.mpg.de/lingua/resources/glossing-rules.php

Corris M, C Manning, S Poetsch \& J Simpson 2004 'How useful and usable are dictionaries for speakers of Australian Indigenous languages?' International Journal of Lexicography 17 (1): 33-67.

Durie M, B Daud \& M Hasan 1994 'Acehnese' in C Goddard \& A Wierzbicka (eds) Semantic and Lexical Universals: theory and empirical findings. Amsterdam: John Benjamins. pp. 171-202.

Elliot AJ \& MA Maier 2014 'Color psychology: effects of perceiving color on psychological functioning in humans' Annual Review of Psychology 65: 95-120.

Gaby AR 2006 'The Thaayorre 'true man': lexicon of the human body in an Australian language' Language Sciences 28 (2-3): 201-220.

Goddard C 1989 'Issues in Natural Semantic Metalanguage' Quaderni di Semantica 10(1): 51-64.

Goddard C 1994a 'Semantic theory and semantic universals' in C Goddard \& A Wierzbicka (eds) Semantic and Lexical Universals: theory and empirical findings. Amsterdam: John Benjamins. pp. 7-30.

Goddard C 1994b 'Lexical primitives in Yankunytjatjara' in C Goddard \& A Wierzbicka (eds) Semantic and Lexical Universals: theory and empirical findings. Amsterdam: John Benjamins. pp. 229-262.

Goddard C 2000 'Polysemy: a problem of definition' in Y Ravin \& C Leacock (eds) Polysemy: Theoretical and Computational Approaches. Oxford: Oxford University Press. pp. 129-151.

Goddard C 2001 'Lexico-semantic universals: A critical overview' Linguistic Typology 5(1): $1-66$.

Goddard C 2002 'The search for the shared semantic core of all languages' in C Goddard \& A Wierzbicka (eds) Meaning and Universal Grammar: theory and empirical findings Amsterdam: John Benjamins. pp. 5-40.

Goddard C 2008 'Natural Semantic Metalanguage: the state of the art' in C Goddard Crosslinguistic Semantics Amsterdam: John Benjamins. pp. 1-34.

Goddard C 2011 Semantic Analysis: a practical introduction (revised 2nd edn) Oxford: Oxford University Press.

Goddard C (ed) 2008 Cross-linguistic Semantics Amsterdam: John Benjamins. 
Goddard C \& N Thieberger 1997 'Lexicographic research on Australian Aboriginal languages 1968-1993' in D Tryon \& M Walsh (eds) Boundary Rider: essays in honour of Geoffrey O'Grady (Pacific Linguistics C-136) Canberra: Australian National University. http://hdl.handle.net/11343/29017

Goddard C \& A Wierzbicka 1994 'Introducing lexical primitives' in C Goddard \& A Wierzbicka (eds) Semantic and Lexical Universals: theory and empirical findings. Amsterdam: John Benjamins. pp. 31-56.

Goddard C \& A Wierzbicka 2014a Words and Meanings. Lexical Semantics Across Domains, Languages and Cultures Oxford: Oxford University Press.

Goddard C \& A Wierzbicka 2014b 'Semantic fieldwork and lexical universals' Studies in Language 38(1): 80-127.

Goddard C \& A Wierzbicka (eds) 1994 Semantic and Lexical Universals: theory and empirical findings. Amsterdam: John Benjamins.

Goddard C \& A Wierzbicka (eds) 2002 Meaning and Universal Grammar: theory and empirical findings Amsterdam: John Benjamins.

Hale KL 1974 Warlpiri-English Vocabulary Alice Springs: Institute for Aboriginal Development.

Hale KL 1981 'Preliminary remarks on the grammar of part-whole relations in Warlpiri' in J Hollyman \& A Pawley (eds) Studies in Pacific Languages \& Cultures in honour of Bruce Biggs Auckland: Linguistic Society of New Zealand. pp. 333-344.

Hale KL 1983 'A lexicographic study of some Australian languages: project description' in PK Austin (ed) Papers in Australian Linguistics no. 15 Australian Aboriginal Lexicography (Pacific Linguistics A-66) Canberra: Australian National University. pp. 71107.

Hale KL \& M Laughren 1982 Warlpiri Dictionary Project: Body part domain: Preliminary remarks on the range of meanings and types of semantic relations in the body part domain in Warlpiri.

Keesing RM 1994 'Radical cultural difference: anthropology's myth' in M Pütz (ed) Language Contact and Language Conflict Amsterdam: John Benjamins. pp. 3-24.

Laughren M 1984 'Remarks on the semantics of body part terminology in Warlpiri' Language in Central Australia 1: 1-9.

Laughren M 1992 'Secondary predication as a diagnostic of underlying structure in PamaNyungan languages' in IM Roca (ed) Thematic Structure: its role in grammar Berlin: Foris. pp. 199-246.

Laughren M \& D Nash 1983 'Warlpiri Dictionary Project: aims, method, organization and problems of definition' in PK Austin (ed) Papers in Australian Linguistics no. 15 Australian Aboriginal Lexicography (Pacific Linguistics A-66) Canberra: Australian National University. pp. 109-133.

Laughren M \& R Hoogenraad 1996 A Learner's Guide to Warlpiri: Tape Course for Beginners: Wangkamirlipa Warlpiriki. Alice Springs: IAD Press.

Laughren M., K Hale \& Warlpiri Lexicography Group 2006 Warlpiri-English encyclopaedic dictionary. Electronic files. St. Lucia: University of Queensland.

Lehmann C 2004 'Interlinear morphemic glossing' in G Booij, C Lehmann, J Mugdan \& S Skopeteas (eds.) Morphologie. Ein internationals Handbuch zur Flexion und Wortbildung. 2. Halbband. Berlin: Walter de Gruyter. pp. 1834-1857. Available at http://www.folialinguistica.com/documents/Interlinearmorphemicglossing.pdf

Majid A, NJ Enfield \& M van Staden 2006 'Cross-linguistic categorisation of the body: Introduction’ Language Sciences 28 (2-3): 137-147.

Majid A, NJ Enfield \& M van Staden (eds) 2006 'Parts of the body: cross-linguistic categorisation' Special Issue of Language Sciences 28 (2-3). 
Manning CD, K Jansz \& N Indurkhya 2001 'Kirrkirr: software for browsing and visual exploration of a structured Warlpiri dictionary' Literary and Linguistic Computing 16 (2): $135-151$.

Mooney A 2014 Human Rights and the Body: hidden in plain sight Farnham UK: Ashgate.

Nash D 1986a Topics in Warlpiri Grammar New York: Garland.

Nash D 1986b 'Index of Warlpiri suffixes and enclitics'. Appendix to Nash 1986a Available at: http://www.anu.edu.au/linguistics/nash/aust/wlp/wlp-lx-ref.html

Nash D 2014 'Alternating generations again again: a response to Wierzbicka on generation moieties' in L Gawne \& J Vaughan (eds) Selected Papers from the 44th Conference of the Australian Linguistic Society, 2013 University of Melbourne. http://hdl.handle.net/11343/40958.

Nash D \& PJ Patrick 1985 'Warlpiri Dictionary update' Language in Central Australia 3: 2324.

Nicholls C 2013 'It's time we draft Aussie Rules to tackle Indigenous mathematics' The Conversation [http://theconversation.com/its-time-we-draft-aussie-rules-to-tackleindigenous-mathematics-15032]

Patrick PJ 1984 'News: Lajumanu Warlpiri Dictionary' Language in Central Australia 1:55.

Peeters B (ed) 2006 Semantic Primes and Universal Grammar: empirical evidence from the Romance languages Amsterdam: John Benjamins.

Ponsonnet M 2012 'Body-parts in Dalabon and Barunga Kriol: matches and mismatches' in M Ponsonnet, L Dao \& M Bowler (eds) Proceedings of the 42nd Australian Linguistic Society Conference 2011 Australian Linguistic Society. pp. 351-387. http://hdl.handle.net/1885/9404.

Priestley C In press 'Some key body parts and polysemy: a case study from Koromu (Kesawai)' in Z Ye (ed) The Semantics of Nouns Oxford: Oxford University Press.

Riemer N 2005 The Semantics of Polysemy: reading meaning in English and Warlpiri Berlin: Mouton de Gruyter.

Simpson J 1991 Warlpiri Morpho-Syntax: A Lexicalist Approach Dordrecht: Kluwer.

Swartz, S (compiler) n.d. Online Interactive Warlpiri Dictionary. Hosted by AuSIL http://ausil.org/Dictionary/Warlpiri/lexicon/index.htm

Weinreich U 1962 'Lexicographic definition in descriptive semantics' Problems in Lexicography 21: 25-44.

Wierzbicka A 1972 Semantic Primitives Frankfurt: Athenäum.

Wierzbicka A 1980 Lingua Mentalis: The semantics of natural language Sydney: Academic.

Wierzbicka A 1983 'Semantics and lexicography: Some comments on the Warlpiri Dictionary Project' in PK Austin (ed) Papers in Australian Linguistics no. 15 Australian Aboriginal Lexicography (Pacific Linguistics A-66) Canberra: Australian National University. pp. 135-144.

Wierzbicka A 1990 'The meaning of color terms: semantics, culture, and cognition' Cognitive Linguistics 1 (1): 99-150.

Wierzbicka A 1996 Semantics: primes and universals Oxford: Oxford University Press.

Wierzbicka A 2002 'Semantic primes and universal grammar in Polish' in C Goddard \& A Wierzbicka (eds) Meaning and Universal Grammar: theory and empirical findings (vol 2) Amsterdam: John Benjamins. pp. 65-144.

Wierzbicka A 2007 'Bodies and their parts: an NSM approach to semantic typology' Language Sciences 29(1): 14-65.

Wierzbicka A 2008 'Why there are no 'colour universals' in language and thought' Journal of the Royal Anthropological Institute 14: 407-425. 
Wierzbicka A 2009 'All people eat and drink: does this mean that 'eat' and 'drink' are universal human concepts?' in J Newman (ed) The Linguistics of Eating and Drinking Amsterdam: John Benjamins. pp. 65-89.

Wierzbicka A 2014a " "Pain" and "suffering" in cross-linguistic perspective' in C Goddard \& $\mathrm{Z}$ Ye (eds) "Happiness" and "pain" across languages and cultures. Special issue of International Journal of Language and Culture 1(2): 147-173. [In press as C Goddard \& Z Ye (eds) "Happiness" and "pain" across languages and cultures Benjamins Current Topics]

Wierzbicka A 2014b 'Can There be Common Knowledge Without a Common Language?: German Pflicht versus English Duty' Common Knowledge 21(1): 141-171.

Wierzbicka A 2015 'The meaning of color words in cross-linguistic perspective' in AJ Elliot, MD Fairchild \& A Franklin (eds) The Handbook of Color Psychology Cambridge: Cambridge University Press.

Wierzbicka A In press 'How much longer can the Berlin and Kay paradigm dominate visual semantics? English, Russian and Warlpiri seen 'from the native's point of view' in D Young (ed) Rematerializing Colour Herefordshire, UK: Sean Kingston Publishing. 